\title{
Glucosamine increases hyaluronic acid production in human osteoarthritic synovium explants
}

\author{
EJ Uitterlinden*1, JLM Koevoet ${ }^{1,2}$, CF Verkoelen ${ }^{3}$, SMA Bierma-Zeinstra ${ }^{4}$, \\ H Jahr1 ${ }^{1}$ H Weinans ${ }^{1}$, JAN Verhaar ${ }^{1}$ and GJVM van Osch ${ }^{1,2}$
}

\author{
Address: ${ }^{1}$ Dept. of Orthopaedics, Erasmus MC, University Medical Centre Rotterdam, the Netherlands, ${ }^{2}$ Dept. of Otorhinolaryngology, Erasmus \\ MC, University Medical Centre Rotterdam, the Netherlands, ${ }^{3}$ Dept. of Urology, Erasmus MC, University Medical Centre Rotterdam, the \\ Netherlands and ${ }^{4}$ Dept. of General Practice, Erasmus MC, University Medical Centre Rotterdam, the Netherlands \\ Email: EJ Uitterlinden* - e.uitterlinden@erasmusmc.nl; JLM Koevoet - j.l.m.koevoet@erasmusmc.nl; \\ CF Verkoelen - e.uitterlinden@erasmusmc.nl; SMA Bierma-Zeinstra - s.bierma-zeinstra@erasmusmc.nl; H Jahr - h.jahr@erasmusmc.nl; \\ H Weinans - h.weinans@erasmusmc.nl; JAN Verhaar - j.verhaar@erasmusmc.nl; GJVM van Osch - g.vanosch@erasmusmc.nl \\ * Corresponding author
}

Published: II September 2008

BMC Musculoskeletal Disorders 2008, 9:120 doi:10.1 I86/147|-2474-9-120

This article is available from: http://www.biomedcentral.com/I47/-2474/9/120

(C) 2008 Uitterlinden et al; licensee BioMed Central Ltd.

This is an Open Access article distributed under the terms of the Creative Commons Attribution License (http://creativecommons.org/licenses/by/2.0), which permits unrestricted use, distribution, and reproduction in any medium, provided the original work is properly cited.
Received: 22 January 2008

Accepted: II September 2008

\begin{abstract}
Background: Glucosamine (GlcN) used by patients with osteoarthritis was demonstrated to reduce pain, but the working mechanism is still not clear. Viscosupplementation with hyaluronic acid (HA) is also described to reduce pain in osteoarthritis. The synthesis of $\mathrm{HA}$ requires $\mathrm{GlcN}$ as one of its main building blocks. We therefore hypothesized that addition of $\mathrm{GlcN}$ might increase HA production by synovium tissue.
\end{abstract}

Methods: Human osteoarthritic synovium explants were obtained at total knee surgery and precultured for I day. The experimental conditions consisted of a 2 days continuation of the culture with addition of N-Acetyl-glucosamine (GlcN-Ac; $5 \mathrm{mM}$ ), glucosamine-hydrochloride (GlcN-HCl; 0.5 and $5 \mathrm{mM}$ ), glucose (Gluc; 0.5 and $5 \mathrm{mM}$ ). Hereafter HA production was measured in culture medium supernatant using an enzyme-linked binding protein assay. Real time RT-PCR was performed for hyaluronic acid synthase (HAS) I, 2 and 3 on RNA isolated from the explants.

Results: $0.5 \mathrm{mM}$ and $5 \mathrm{mM} \mathrm{GlcN}-\mathrm{HCl}$ significantly increased $\mathrm{HA}$ production compared to control (approximately 2 - 4-fold), whereas GlcN-Ac had no significant effect. Addition of $5 \mathrm{mM}$ Gluc also increased HA production (approximately 2-fold), but $0.5 \mathrm{mM}$ Gluc did not. Gene expression of the HA forming enzymes HAS I, 2 and 3 was not altered by the addition of GlcN or Gluc.

Conclusion: Our data suggest that exogenous $\mathrm{GlcN}$ can increase HA production by synovium tissue and is more effective at lower concentrations than Gluc. This might indicate that GlcN exerts its potential analgesic properties through stimulation of synovial HA production.

\section{Background}

Glucosamine $(\mathrm{GlcN})$ is popular among patients suffering from osteoarthritis (OA). Although the efficacy of GlcN in $\mathrm{OA}$ is still under debate, subgroup analysis in patients with moderate-to-severe pain in a recent large NIH trial indicated that glucosamine hydrochloride ( $\mathrm{GlcN}-\mathrm{HCl})$ might have a positive effect on pain [1]. Two clinical studies indicated that GlcN might have structure modifying 
effects on cartilage in knee OA [2,3]. The claim of structure modifying properties of GlcN is mostly based on the effects on cartilage. However, cartilage is not innervated and thus pain reduction after GlcN administration, as has been reported in the previously mentioned NIH trial, can therefore not be explained by the effect of GlcN on cartilage tissue. Considering pain reduction in OA, viscosupplementation with hyaluronic acid (HA) has been shown to have beneficial effects on both pain and function in patients with knee OA [4]. Since GlcN is an important building block of HA and HA is found in high amounts in articular joints, increasing HA production through the administration of GlcN might be a way to explain the pain relieving effect of GlcN. HA is synthesized by hyaluronic acid synthases (HAS) which covalently link the monomeric building blocks glucuronic acid and N-Acetyl-glucosamine (GlcN-Ac) in an alternating fashion. Hence, if the HAS enzymes are at hand, availability of its building blocks is another prerequisite for the synthesis of HA. But, more availability of substrate does not necessarily have to lead to more HA.

The aim our study was to evaluate whether GlcN derivatives have an effect on HA production in a human synovium explant model. Specifically, we investigated if HA production can be stimulated by adding GlcN and if GlcN affects gene expression of the HAS enzymes.

\section{Methods}

\section{Explant culture}

Human synovium was obtained from patients suffering from knee OA at time of total knee arthroplasty operation (12 patients, age 48-70 male:female ratio 1:2, with approval of the Ethical Committee number MEC 2004140). To remove any remaining synovial fluid or blood, raw material was rinsed three times in physiological saline. From this raw material explants of approximately $3 \mathrm{~mm}^{2}$ each were created with a scalpel and pooled in a Petri dish. Per condition, explants were randomly taken from the Petri dish and cultured in a 6-well plate with 3 $\mathrm{ml}$ culture medium per well. During the whole experiment this culture medium consisted of low glucose $(1000$ $\mathrm{mg} / \mathrm{l} \mathrm{l}=5.55 \mathrm{mM}$ ) D-MEM (Gibco, Grand Island, NY), supplemented with $10 \%$ fetal calf serum (containing 0.5 $\mathrm{mM}$ glucose), $50 \mu \mathrm{g} / \mathrm{ml}$ gentamicin, $1.5 \mu \mathrm{g} / \mathrm{ml}$ fungizone. The total amount of explants per patient differed. Therefore, care was taken to use an equal number of explants per culture condition within one patient. In the final analysis, results were corrected for total sample weight.

After a 24 hour pre-culture period (day 1), the culture medium was refreshed and the actual experiment was started by supplementing the culture medium with different derivatives for 48 hours (day 2-3).
In the first series of experiments ( $\mathrm{N}=6$ patients) the effect of different GlcN derivatives on HA production was studied. Therefore, the culture medium was supplemented with GlcN-HCl (Sigma, St. Louis, MO) or GlcN-Ac (Sigma, St. Louis, MO) at $5 \mathrm{mM}$.

In the second series of experiments $(\mathrm{N}=6$ patients $)$ we investigated the effect of different GlcN concentrations on HA production. We also investigated the effect of glucose (Gluc) concentrations similar to that of GlcN on HA production, since in vivo GlcN is being formed from Gluc. Finally, in the second series of experiments the effect of GlcN and Gluc on HAS gene expression was studied. In this second series of experiments the culture medium was supplemented with GlcN-HCl or Gluc (Sigma, St. Louis, $\mathrm{MO}$ ) at $0.5 \mathrm{mM}$ and $5 \mathrm{mM}$, respectively. In all experiments the culture medium without GlcN or extra Gluc supplementation was used as a control.

For all experiments, at day 3 medium supernatant was stored at $-20^{\circ} \mathrm{C}$ for analysis, explants were harvested and the wet weight per sample was determined. The explants from experiment 2 were snap frozen in liquid nitrogen for RNA isolation.

\section{Analysis}

HA synthesis was measured in culture medium using an enzyme-linked binding protein assay (Hyaluronic Acid test Kit, Corgenix Inc., Westminster, CO) in a 96 wells plate. The wells were coated with HA binding protein from bovine cartilage to capture HA and an enzyme-conjugated version of HA binding protein to detect and measure $\mathrm{HA}$ in the sample using a spectrophotometer at 450 $\mathrm{nm}$ (650 nm reference). HA from rooster comb was used as standard. The resulting amount of HA in the culture medium was corrected for sample weight. For display purposes, these values were expressed relative to the control condition on day 3 .

The wet weight per sample of the snap frozen explants from experiment 2 was determined and the frozen synovium was then processed using the Mikro-Dismembrator $S^{\circledast}$ (B. Braun Biotech International GmbH, Melsungen, Germany). RNA was extracted using RNA-Bee ${ }^{\mathrm{TM}}$ (TELTEST, Inc; Friendswood, TX, USA) according to manufacturer's guidelines and subsequently precipitated with 2 propanol. RNA was further purified using RNeasy Micro Kit (Qiagen, Venlo, The Netherlands) with on-column DNA-digestion. Total RNA was quantified accurately using a NanoDrop ${ }^{\mathrm{TM}} 1000$ spectrophotometer (Nanodrop technologies, Wilmington, DE) according to manufacturer's instructions and 500 ng total RNA of each sample was reverse transcribed into cDNA using RevertAid ${ }^{\mathrm{TM}}$ First Strand cDNA Synthesis Kit (MBI Fermentas, Germany). TaqMan $^{\circledR}$ assays were performed on an ABI Prism 7000 for 
HAS 1, 2 and 3 using an assay-on-demand (Applied Biosystems, Foster City, CA, order numbers HAS1: Hs00758053_m1, HAS2: Hs00193435_m1, HAS3: Hs00193436_m1). Tissue processing and gene expression analysis were performed using the same protocol we described earlier in our study on human osteoarthritic cartilage explants [5].

For each patient the Ct-values of each control and experimental condition were normalized to glyceraldehyde 3phosphate dehydrogenase. Hereafter each experimental condition was expressed relative to the corresponding control condition of the same patient, according to the $2^{-}$ $\Delta \Delta \mathrm{Ct}$ method described by Livak et al. [6,7]. The resulting number of this calculation indicated whether there was an up or down-regulation of gene expression of an experimental condition compared to its paired untreated control. Thereafter, for each subset of experimental conditions the median of these numbers was calculated. For graphical display purposes only the $2^{-\Delta \Delta \mathrm{Ct}}$ values were expressed as a ${ }^{10} \mathrm{LOG}$. For statistical analysis a Friedman test with post-hoc Wilcoxon signed ranks test was performed on the amount of HA in the culture medium corrected for sample weight (HA production) and on the normalized Ct values (gene expression), using SPSS 11.5.0 (SPSS Inc., Chicago, IL). A p-value $\leq 0.05$ was considered to indicate statistically significant differences.

\section{Results}

In the first set of experiments, the amount of HA in the medium was increased significantly 3.66 fold by the addition of $5 \mathrm{mM}$ GlcN-HCl when compared to the control condition (Fig. 1). The increase after addition of $5 \mathrm{mM}$ GlcN-Ac was not statistically significant.

In the second set of experiments, in which samples from 6 other patients were used, HA in the culture medium was significantly increased by $0.5 \mathrm{mM}$ GlcN-HCl (204\%) and $5 \mathrm{mM}$ GlcN-HCl (207\%) and by addition of $5 \mathrm{mM}$ Gluc (178\%), but not by $0.5 \mathrm{mM}$ Gluc (Fig 2).

Furthermore, all three HAS isoforms were expressed in the synovium explants. No statistically significant difference in gene expression was found for the experimental conditions, compared to the control condition (Fig. 3).

\section{Discussion}

Addition of $0.5 \mathrm{mM}$ or $5 \mathrm{mM}$ GlcN-HCl to human osteoarthritic synovium explants in vitro led to more HA in the medium when compared to the control condition. $5 \mathrm{mM}$ GlcN-Ac did not have a significant effect on medium HA concentration.

To this date several in vitro studies have been published on the possible working mechanisms of GlcN in OA. Interference with catabolic activities and stimulation of anabolic activities on chondrocytes have both been reported for GlcN in vitro. Studies investigating the influ-



\section{Figure I}

HA after addition of 5 mM GICN-Ac or GlcN-HCl to human synovium explants. Amount of hyaluronic acid secreted into culture medium after 48 hours treatment of human osteoarthritic synovium explants with $5 \mathrm{mM} G \mathrm{Gl}-\mathrm{Ac}(\mathrm{N}=6)$ or 5 $\mathrm{mM} \mathrm{GlcN}-\mathrm{HCl}(\mathrm{N}=6)$ for 2 days. Values are expressed relative to the non-treated (NT) control condition which is set at $100 \%(N=6$, first bar $)$. $*$ indicates a statistically significant difference $(p=0.028)$. 


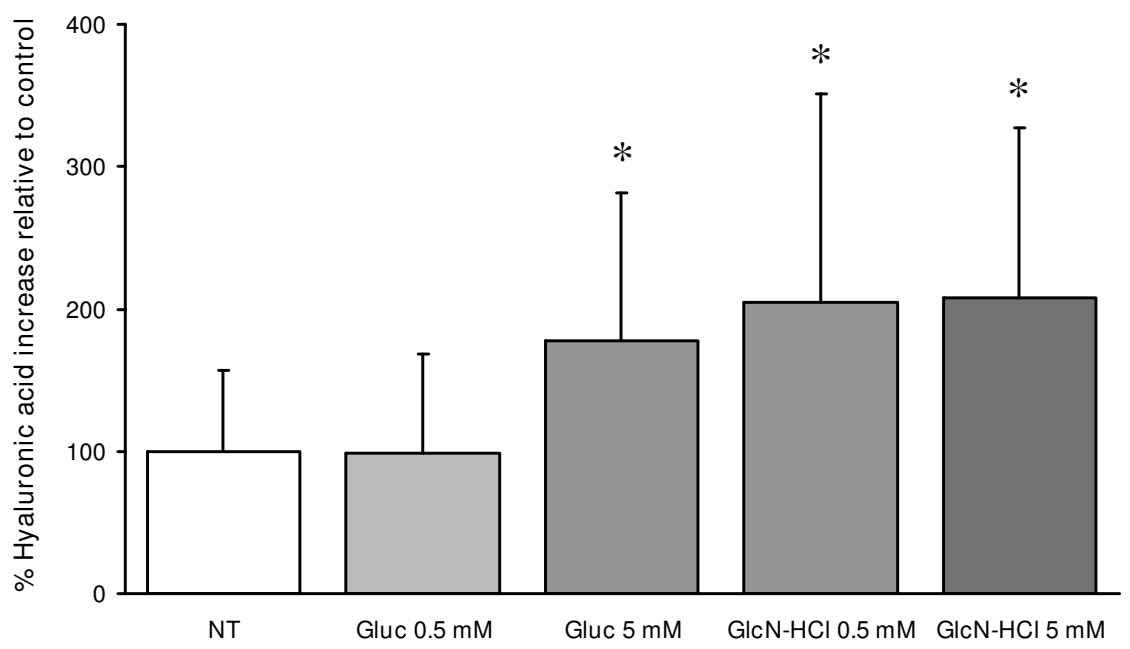

\section{Figure 2}

HA after addition of 0.5 and $5 \mathrm{mM} \mathrm{GIcN-HCl}$ or Gluc to human synovium explants. Amount of hyaluronic acid secreted into culture medium after 48 hours treatment of human osteoarthritic synovium explants with $0.5 \mathrm{mM} \mathrm{GlcN}-\mathrm{HCl}$ ( $\mathrm{N}$ =6), $5 \mathrm{mM} \mathrm{GlcN}-\mathrm{HCl}(\mathrm{N}=6), 0.5 \mathrm{mM}$ Gluc $(\mathrm{N}=5)$ or $5 \mathrm{mM} \mathrm{Gluc}(\mathrm{N}=6)$ for 2 days. Values are expressed relative to the non-treated $(\mathrm{NT})$ control condition which is set at $100 \%(\mathrm{~N}=6$, first bar $)$. $*$ indicates a statistically significant difference $(\mathrm{p}=$ 0.028).

ence of GlcN on enzymatic extra-cellular matrix breakdown of cartilage, with a culture system using interleukin1, lipopolysaccharide or retinoic acid to induce catabolic effects, reported less matrix metalloproteinase activity and aggrecanase activity by addition of GlcN [8-13]. Studies considering the possible anabolic effects of GlcN proposed that addition of GlcN led to more glycosaminoglycan production by chondrocytes, since GlcN is the basic

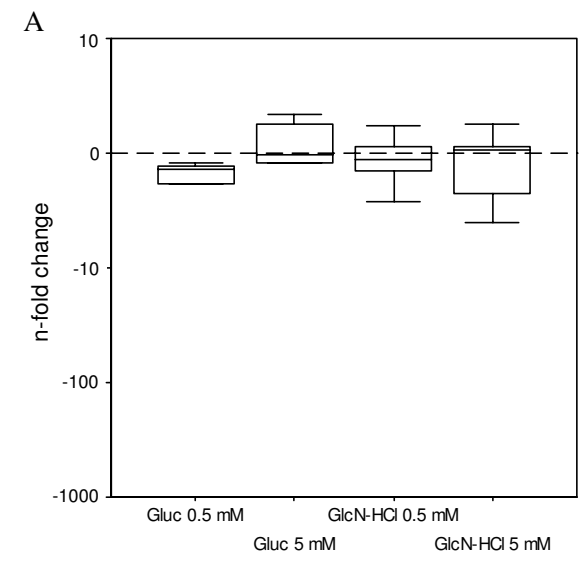

HAS 1

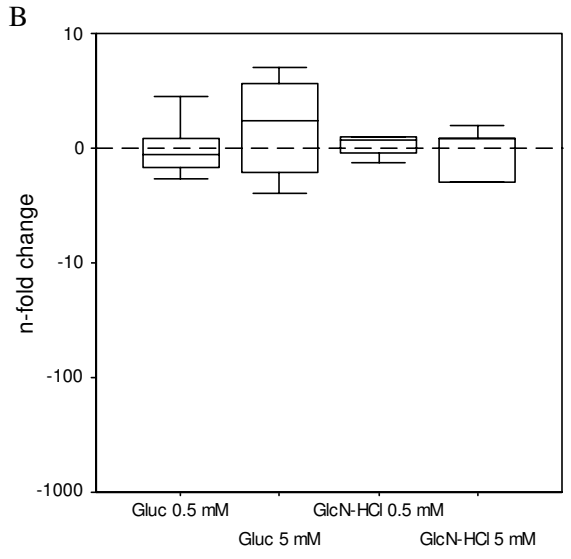

HAS 2

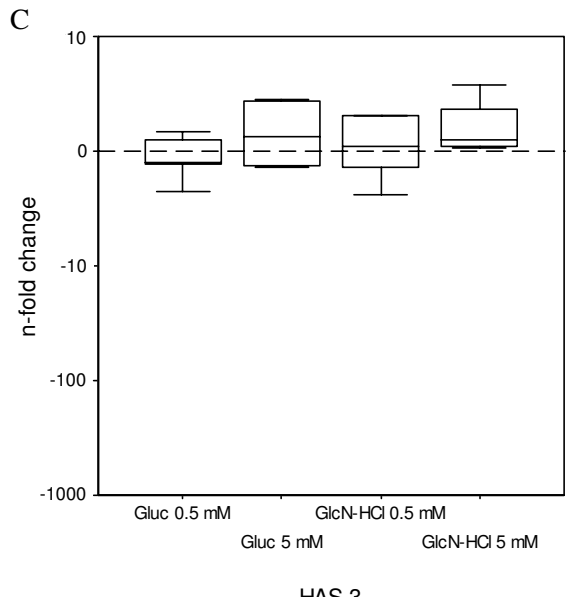

HAS 3

\section{Figure 3}

HAS gene expression after addition of GIcN-HCI or Gluc to human synovium explants. Change in HAS gene expression in human osteoarthritic synovium explants after culture with glucosamine or glucose. Synovium explants were precultured for I day, followed by 2 days of treatment with $0.5 \mathrm{mM} \mathrm{GlcN}-\mathrm{HCl}(\mathrm{N}=6), 5 \mathrm{mM} \mathrm{GlcN}-\mathrm{HCl}(\mathrm{N}=5), 0.5 \mathrm{mM}$ Gluc $(\mathrm{N}$ $=5$ ) and $5 \mathrm{mM}$ Gluc $(\mathrm{N}=6$ ). The n-fold change for HASI (panel A), HAS2 (panel B) and HAS3 (panel C), normalized to glyceraldehyde 3-phosphate dehydrogenase and relative to the untreated control (indicated by the dotted line) is displayed on the vertical axis. Negative values indicate down-regulation and positive values indicate up-regulation of gene expression. No statistically significant differences were found. 
building block of glycosaminoglycan molecules $[9,14$ 17]. These studies were performed with chondrocytes of different species.

Being a rate-limiting precursor in HA synthesis, GlcN was suggested earlier to exert its effects in OA influencing synovial HA synthesis $[18,19]$. However, direct scientific proof for this was still absent. To our knowledge this is the first study that investigated the effect of GlcN on human OA synovium explants.

In experiment 1 with synovium samples from 6 patients addition of $5 \mathrm{mM}$ GlcN-Ac did not lead to a significant increase in medium HA. Therefore in experiment 2, in which samples from 6 other patients were used, only the effects of the derivative $\mathrm{GlcN}-\mathrm{HCl}$ were tested at different concentrations and relative to Gluc treatment. In one of our earlier studies using bovine chondrocytes we also found that GlcN-Ac had a different effect on glycosaminoglycan production when compared to $\mathrm{GlcN}-\mathrm{HCl}$ [20]. We speculate that this difference might be due to in the interference of the covalently bound acetyl group as opposed to the ionically bound, and therefore easy to dissolve, hydrochloride salt.

HA is found in almost all tissues, and plays key roles in many cellular processes such as migration, proliferation, differentiation and regulation of matrix organization [21]. $\mathrm{HA}$ is one of the main components of synovial fluid in articular joints and plays a major role in joint lubrication and in maintaining joint homeostasis [22]. In inflammatory joints, lower concentration of HA as well as lower molecular weight of HA have been described [23]. Size and concentration of HA determine the viscoelastic properties as well as regulate the inflammatory and tissue repair responses $[24,25]$. HA was also shown to be able to have anti-inflammatory effects on OA specific cytokines by down-regulation of tumor necrosis factor alpha, interleukin-8 [26]. HA, a polymer of alternating glucuronic acid and GlcN-Ac units is being synthesized at the inside of the cell at the plasma membrane, and then released into the extracellular matrix [27]. In accordance with Recklies et al. our results demonstrate that all 3 isoforms of HAS, the enzyme responsible for the synthesis of HA, are expressed by synovium [28]. Recklies et al. observed that the HAS1 message levels were always more abundant than that for HAS2 in synovial cells, and that the HAS3 message levels were always least abundant. In experiment 2, our mean Ct values showed a similar trend (data not shown). Addition of GlcN-HCl or Gluc did not alter HAS gene expression significantly. Thus, direct up-regulation of HAS gene expression does not seem to be the explanation for the increased amount of HA in the medium in our experiments. Since HAS gene expression was not affected by GlcN, apart from simply providing more building blocks, GlcN could also have played a role in HA synthesis by influencing HAS enzymatic activity or protein levels. In the current study design this was not investigated, and therefore this possibility can not be commented on.

The increased amount of HA in the culture medium might be explained by the fact that addition of GlcN-HCl simply led to more building blocks that are required for the synthesis of HA. Our results showed that a concentration of exogenous GlcN ten times lower than the medium Gluc concentration already led to significantly more HA production. This indicated a more effective and perhaps specific effect of exogenous GlcN as opposed to endogenous GlcN that is formed intracellular using medium Gluc as substrate.

The major limitation of our study was the use of relatively high concentrations of GlcN when compared to the in vivo situation. A recent report by Persiani et al. [29] showed that synovial GlcN concentration varied between 3 and 18 $\mu \mathrm{M}$ after oral administration at the therapeutic dose of $1500 \mathrm{mg}$ once-a-day. In many earlier reports, including our own, much higher concentration have been used for in-vitro studies [5,10-13,20,30-34]. In chondrocytes it has been demonstrated that exogenous GlcN was incorporated in newly formed chondroitin sulphate when added at an equimolar concentration with Gluc in the culture medium. When Gluc concentration increased, chondrocytes preferably incorporated GlcN that was endogenously formed from Gluc $[35,36]$. These results suggested that in chondrocytes the GlcN to Gluc ratio played an important role in the utilization and therefore effectiveness of exogenously provided GlcN. Since we did not know whether this was also the case for synovium, we decided to use an equimolar and ten times lower GlcN concentration compared to medium Gluc concentration.

When trying to translate our in vitro results to clinical applicability of GlcN, the intra-articular GlcN concentration that can be reached after administration of GlcN to the patient is reason of concern and thus weakens the direct clinical relevance of our work. Since the first studies were performed on the effect of GlcN there has been debate on this topic. When $\mathrm{GlcN}-\mathrm{HCl}$ was administered to horses in a single dose, intravenously as well as orally, in a dosage per kg bodyweight at clinically relevant levels, GlcN was still detectable in synovial fluids 6 hours after it was nearly completely cleared from the serum [37]. Although GlcN can thus be retained in joint fluid, it must still be questioned whether the levels of $0.5 \mathrm{mM}$ or $5 \mathrm{mM}$ GlcN will ever be reached in the joint. Therefore, future studies should look into the effect of lower GlcN concentrations on synovial HA production. Our result should be interpreted as a proof of concept on the possible working mechanism of GlcN in OA. 


\section{Conclusion}

In conclusion, the results of our experiments suggest that GlcN-HCl increases the production of HA in synovium. Our results were obtained with GlcN concentrations much higher than thus far have been reported in human synovial fluid after oral ingestion of a therapeutic dose [29]. Further studies are needed to investigate the effect of GlcN concentrations more likely to be reached in the human joint, before any decision can be made upon the clinical relevancy of GlcN ingestion on synovial HA production.

\section{Competing interests}

The authors declare that they have no competing interests.

\section{Authors' contributions}

EJU and GJVMvO conceived of the study, developed the design of the explant culture system and wrote the article. JLMK conducted the culture experiments, performed the analysis and contributed to the content of the article. CFV, $\mathrm{HJ}$ and JANV contributed to the design of the study and the content of the article. HW and SMABZ contributed to the content of the article. All authors read and approved the final manuscript.

\section{References}

1. Clegg DO, Reda DJ, Harris CL, Klein MA, O'Dell JR, Hooper MM, Bradley JD, Bingham CO 3rd, Weisman MH, Jackson CG, et al.: Glucosamine, chondroitin sulfate, and the two in combination for painful knee osteoarthritis. N Engl J Med 2006, 354(8):795-808.

2. Reginster JY, Deroisy R, Rovati LC, Lee RL, Lejeune E, Bruyere O Giacovelli G, Henrotin Y, Dacre JE, Gossett C: Long-term effects of glucosamine sulphate on osteoarthritis progression: a randomised, placebo-controlled clinical trial. Lancet 200I, 357(9252):25I-256

3. Pavelka K, Gatterova J, Olejarova M, Machacek S, Giacovelli G, Rovati LC: Glucosamine sulfate use and delay of progression of knee osteoarthritis: a 3-year, randomized, placebo-controlled, double-blind study. Arch Intern Med 2002, I 62(I8):2। I3-2। 23.

4. Bellamy N, Campbell J, Robinson V, Gee T, Bourne R, Wells G: Viscosupplementation for the treatment of osteoarthritis of the knee. Cochrane Database Syst Rev 2006:CD00532I.

5. Uitterlinden EJ, Jahr H, Koevoet JL, Jenniskens YM, Bierma-Zeinstra SM, Degroot J, Verhaar JA, Weinans $H$, van Osch GJ: Glucosamine decreases expression of anabolic and catabolic genes in human osteoarthritic cartilage explants. Osteoarthritis Cartilage 2006, I 4(3):250-257

6. Mandl EW, Jahr H, Koevoet JL, van Leeuwen JP, Weinans $\mathrm{H}$, Verhaar $J A$, van Osch GJ: Fibroblast growth factor-2 in serum-free medium is a potent mitogen and reduces dedifferentiation of human ear chondrocytes in monolayer culture. Matrix Biol 2004, 23(4):23I-24I.

7. Livak KJ Schmittgen TD: Analysis of relative gene expression data using real-time quantitative PCR and the 2(-Delta Delta C(T)) Method. Methods 200I, 25(4):402-408.

8. Orth MW, Peters TL, Hawkins JN: Inhibition of articular cartilage degradation by glucosamine- $\mathrm{HCl}$ and chondroitin sulphate. Equine Vet J Suppl 2002:224-229.

9. Dodge GR, Jimenez SA: Glucosamine sulfate modulates the levels of aggrecan and matrix metalloproteinase- 3 synthesized by cultured human osteoarthritis articular chondrocytes. Osteoarthritis Cartilage 2003, I I(6):424-432.

10. Gouze JN, Bordji K, Gulberti S, Terlain B, Netter P, Magdalou J, Fournel-Gigleux S, Ouzzine M: Interleukin- I beta down-regulates the expression of glucuronosyltransferase I, a key enzyme prim- ing glycosaminoglycan biosynthesis: influence of glucosamine on interleukin-lbeta-mediated effects in rat chondrocytes. Arthritis Rheum 200I, 44(2):35I-360.

II. Sandy JD, Gamett D, Thompson V, Verscharen C: Chondrocytemediated catabolism of aggrecan: aggrecanase-dependent cleavage induced by interleukin-I or retinoic acid can be inhibited by glucosamine. Biochem J 1998, 335(Pt I):59-66.

12. Fenton JI, Chlebek-Brown KA, Caron JP, Orth MW: Effect of glucosamine on interleukin-I-conditioned articular cartilage. Equine Vet J Suppl 2002:21 9-223.

13. Byron CR, Orth MW, Venta PJ, Lloyd JW, Caron JP: Influence of glucosamine on matrix metalloproteinase expression and activity in lipopolysaccharide-stimulated equine chondrocytes. Am J Vet Res 2003, 64(6):666-67I.

14. Bassleer C, Rovati L, Franchimont P: Stimulation of proteoglycan production by glucosamine sulfate in chondrocytes isolated from human osteoarthritic articular cartilage in vitro. Osteoarthritis Cartilage 1998, 6(6):427-434.

15. Bassleer C, Henrotin Y, Franchimont P: In-vitro evaluation of drugs proposed as chondroprotective agents. Int J Tissue React I992, | 4(5):23|-24|.

16. Lippiello L: Glucosamine and chondroitin sulfate: biological response modifiers of chondrocytes under simulated conditions of joint stress. Osteoarthritis Cartilage 2003, I I(5):335-342.

17. Vidal y Plana RR, Bizzarri D, Rovati AL: Articular cartilage pharmacology: I. In vitro studies on glucosamine and non steroidal antiinflammatory drugs. Pharmacol Res Commun 1978, I0(6):557-569.

18. McCarty MF: Enhanced synovial production of hyaluronic acid may explain rapid clinical response to high-dose glucosamine in osteoarthritis. Med Hypotheses 1998, 50(6):507-510.

19. McCarty MF, Russell AL, Seed MP: Sulfated glycosaminoglycans and glucosamine may synergize in promoting synovial hyaluronic acid synthesis. Med Hypotheses 2000, 54(5):798-802.

20. Uitterlinden EJ, Jahr H, Koevoet JL, Bierma-Zeinstra SM, Verhaar JA, Weinans $H$, van Osch G]: Glucosamine reduces anabolic as well as catabolic processes in bovine chondrocytes cultured in alginate. Osteoarthritis Cartilage 2007, I5(I I): I267-1274

21. Laurent TC, Fraser JR: Hyaluronan. Faseb J 1992, 6(7):2397-2404.

22. Laurent TC, Laurent UB, Fraser IR: The structure and function of hyaluronan: An overview. Immunol Cell Biol 1996, 74(2):AI-7.

23. Dahl LB, Dahl IM, Engstrom-Laurent A, Granath K: Concentration and molecular weight of sodium hyaluronate in synovial fluid from patients with rheumatoid arthritis and other arthropathies. Ann Rheum Dis 1985, 44( I 2):817-822.

24. Fam H, Bryant JT, Kontopoulou M: Rheological properties of synovial fluids. Biorheology 2007, 44(2):59-74.

25. Jiang D, Liang J, Noble PW: Hyaluronan in Tissue Injury and Repair. Annu Rev Cell Dev Biol 2007, 23:435-6I.

26. Wang CT, Lin YT, Chiang BL, Lin YH, Hou SM: High molecular weight hyaluronic acid down-regulates the gene expression of osteoarthritis-associated cytokines and enzymes in fibroblast-like synoviocytes from patients with early osteoarthritis. Osteoarthritis Cartilage 2006, I 4(I 2): I237- 247.

27. Prehm P: Hyaluronate is synthesized at plasma membranes. Biochem J 1984, 220(2): 597-600.

28. Recklies AD, White $C$, Melching L, Roughley PJ: Differential regulation and expression of hyaluronan synthases in human articular chondrocytes, synovial cells and osteosarcoma cells. Biochem J 200I, 354(Pt I): 17-24.

29. Persiani S, Rotini R, Trisolino G, Rovati LC, Locatelli M, Paganini D, Antonioli D, Roda A: Synovial and plasma glucosamine concentrations in osteoarthritic patients following oral crystalline glucosamine sulphate at therapeutic dose. Osteoarthritis Cartilage 2007, I 5(7):764-772.

30. Fenton JI, Chlebek-Brown KA, Peters TL, Caron JP, Orth MW: The effects of glucosamine derivatives on equine articular cartilage degradation in explant culture. Osteoarthritis Cartilage 2000, 8(6):444-45I.

31. de Mattei M, Pellati A, Pasello M, de Terlizzi F, Massari L, Gemmati D, Caruso A: High doses of glucosamine- $\mathrm{HCl}$ have detrimental effects on bovine articular cartilage explants cultured in vitro. Osteoarthritis Cartilage 2002, I0(I0):816-825.

32. Fenton JI, Chlebek-Brown KA, Peters TL, Caron JP, Orth MW: Glucosamine $\mathrm{HCl}$ reduces equine articular cartilage degradation in explant culture. Osteoarthritis Cartilage 2000, 8(4):258-265. 
33. Gouze JN, Bianchi A, Becuwe P, Dauca M, Netter P, Magdalou J, Terlain B, Bordji K: Glucosamine modulates IL-I-induced activation of rat chondrocytes at a receptor level, and by inhibiting the NF-kappa B pathway. FEBS Lett 2002, 5 I 0(3): I66-I 70.

34. Mello DM, Nielsen BD, Peters TL, Caron JP, Orth MW: Comparison of inhibitory effects of glucosamine and mannosamine on bovine articular cartilage degradation in vitro. Am J Vet Res 2004, 65(10): 1440-1445.

35. Mroz PJ, Silbert JE: Effects of [3H]glucosamine concentration on $[3 \mathrm{H}]$ chondroitin sulphate formation by cultured chondrocytes. Biochem J 2003, 376(Pt 2):5II-5I5.

36. Mroz PJ, Silbert JE: Use of (3)H-glucosamine and (35)S-sulfate with cultured human chondrocytes to determine the effect of glucosamine concentration on formation of chondroitin sulfate. Arthritis Rheum 2004, 50(I I):3574-3579.

37. Laverty S, Sandy JD, Celeste C, Vachon P, Marier JF, Plaas AH: Synovial fluid levels and serum pharmacokinetics in a large animal model following treatment with oral glucosamine at clinically relevant doses. Arthritis Rheum 2005, 52(1): |8I-191.

\section{Pre-publication history}

The pre-publication history for this paper can be accessed here:

http://www.biomedcentral.com/1471-2474/9/120/pre pub

Publish with Bio Med Central and every scientist can read your work free of charge

"BioMed Central will be the most significant development for disseminating the results of biomedical research in our lifetime. "

Sir Paul Nurse, Cancer Research UK

Your research papers will be:

- available free of charge to the entire biomedical community

- peer reviewed and published immediately upon acceptance

- cited in PubMed and archived on PubMed Central

- yours - you keep the copyright

Submit your manuscript here:

http://www.biomedcentral.com/info/publishing_adv.asp 